\title{
Evapotranspiration Across the Rain-Snow Transition in a Semi-Arid Watershed
}

\author{
Maggi $\mathrm{Kraft}^{1}$ and James McNamara ${ }^{2}$ \\ ${ }^{1} \mathrm{BOI}$ \\ ${ }^{2}$ Boise State University
}

November 18, 2021

\begin{abstract}
The snowpack regime influences the timing of soil water available for transpiration and synchrony with the evapotranspiration (ET) energy demand (air temperature, VPD, and shortwave radiation). Variability of snowmelt timing, soil water availability, and the energy demand results in heterogeneous ET rates throughout a watershed. In this study, we assess how ET and growing season length vary across five sites on an elevational gradient in the Dry Creek Watershed, ID, USA. We compared trends of daily and annual ET between 2012 and 2017 to environmental parameters of soil moisture, air temperature, vapor pressure deficit, snow cover, and precipitation and evaluate how ET varies between sites and what influences annual ET at each site. We observed three trends in ET across the watershed. The first trend is at the low elevation site where the snow cover is not continuous throughout the winter and rain is the dominant precipitation form. The first day of the growing season and ET occurs early in the season when the energy demand is low and soil water is available. Annual ET at the low elevation site is a balance between spring precipitation providing soil water into the summer season and limiting the ET energy demand. The second trend occurs at the middle elevation site located in the rain-snow transition. At this site, ET increases with snow depth and spring precipitation extending the soil water availability into the summer season. At the higher elevation sites, ET is aligned with the energy demand and limited by growing season length. At the high elevation sites, decreasing snow depth and spring precipitation and increasing spring air temperatures result in greater annual ET rates. The observations from this study highlight the influence of environmental parameters and the potential sensitivity of ET to climate change.
\end{abstract}

\section{Hosted file}

ET_paper_main.docx available at https://authorea.com/users/446870/articles/546000evapotranspiration-across-the-rain-snow-transition-in-a-semi-arid-watershed

Hosted file

Table1.docx available at https://authorea.com/users/446870/articles/546000evapotranspiration-across-the-rain-snow-transition-in-a-semi-arid-watershed

Hosted file

Table2.docx available at https://authorea.com/users/446870/articles/546000evapotranspiration-across-the-rain-snow-transition-in-a-semi-arid-watershed 


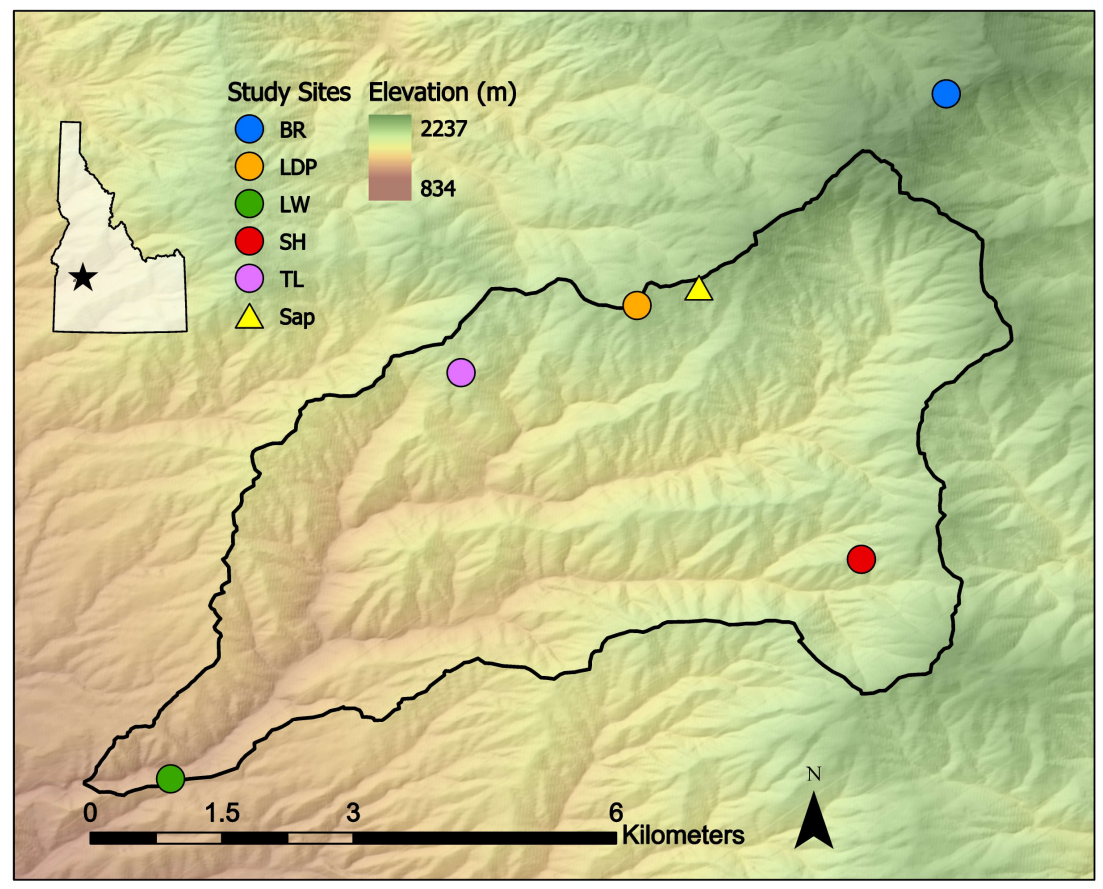



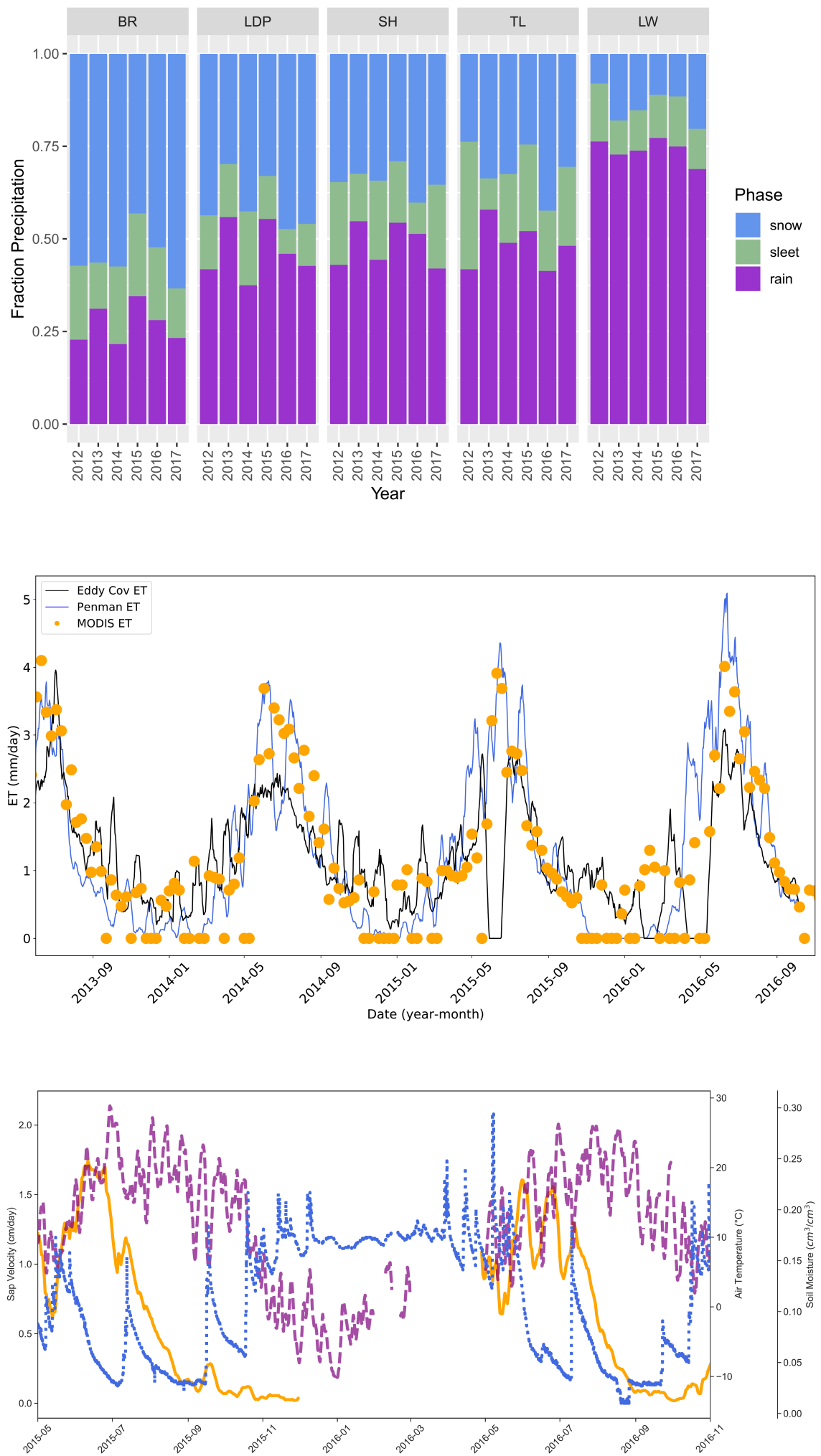

Soil Moisture $\left(\mathrm{cm}^{3} / \mathrm{cm}^{3}\right) \quad$ Sap Velocity (cm/day) -..-. Air Temperature $\left({ }^{\circ} \mathrm{C}\right)$ 

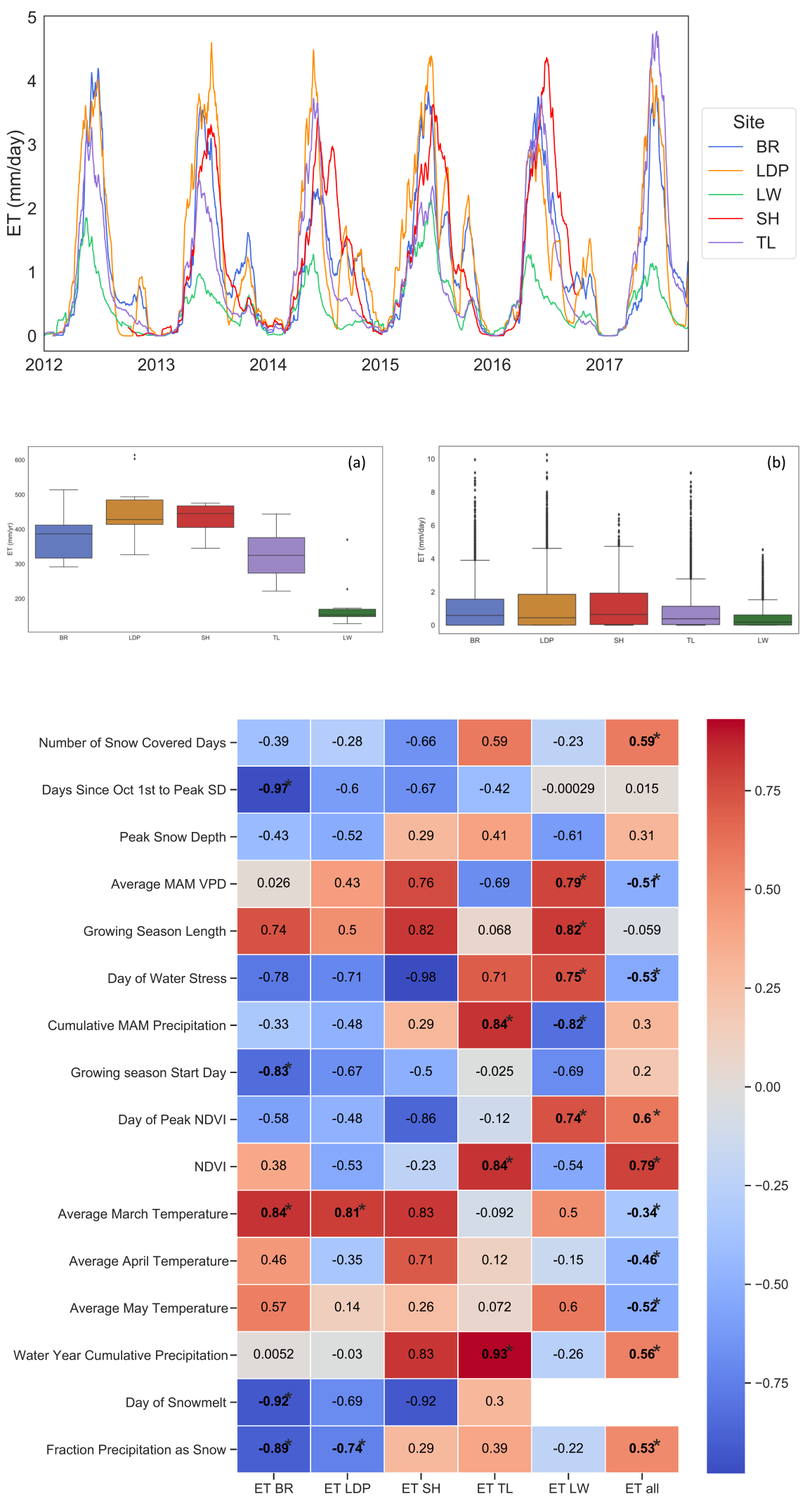

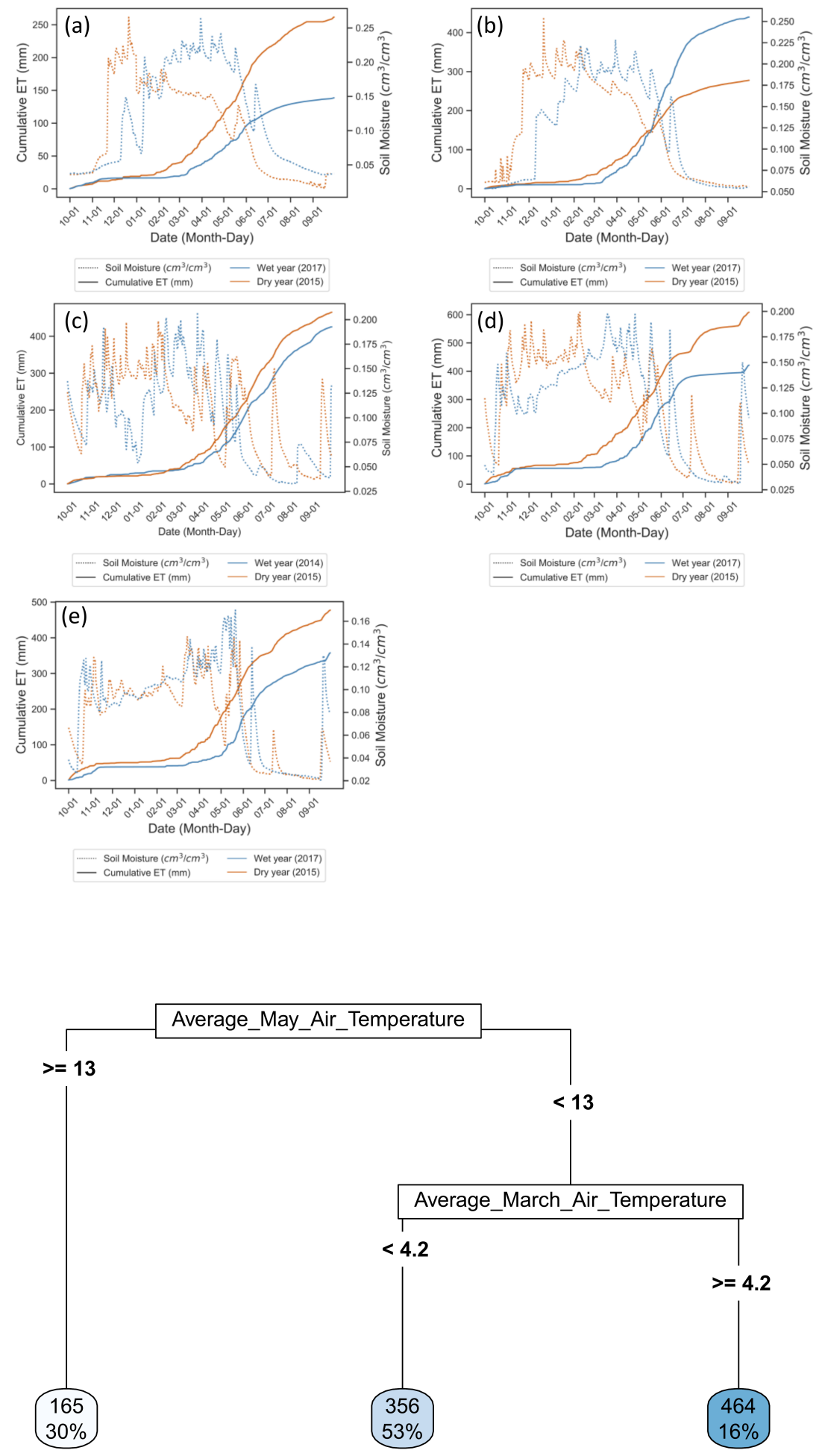

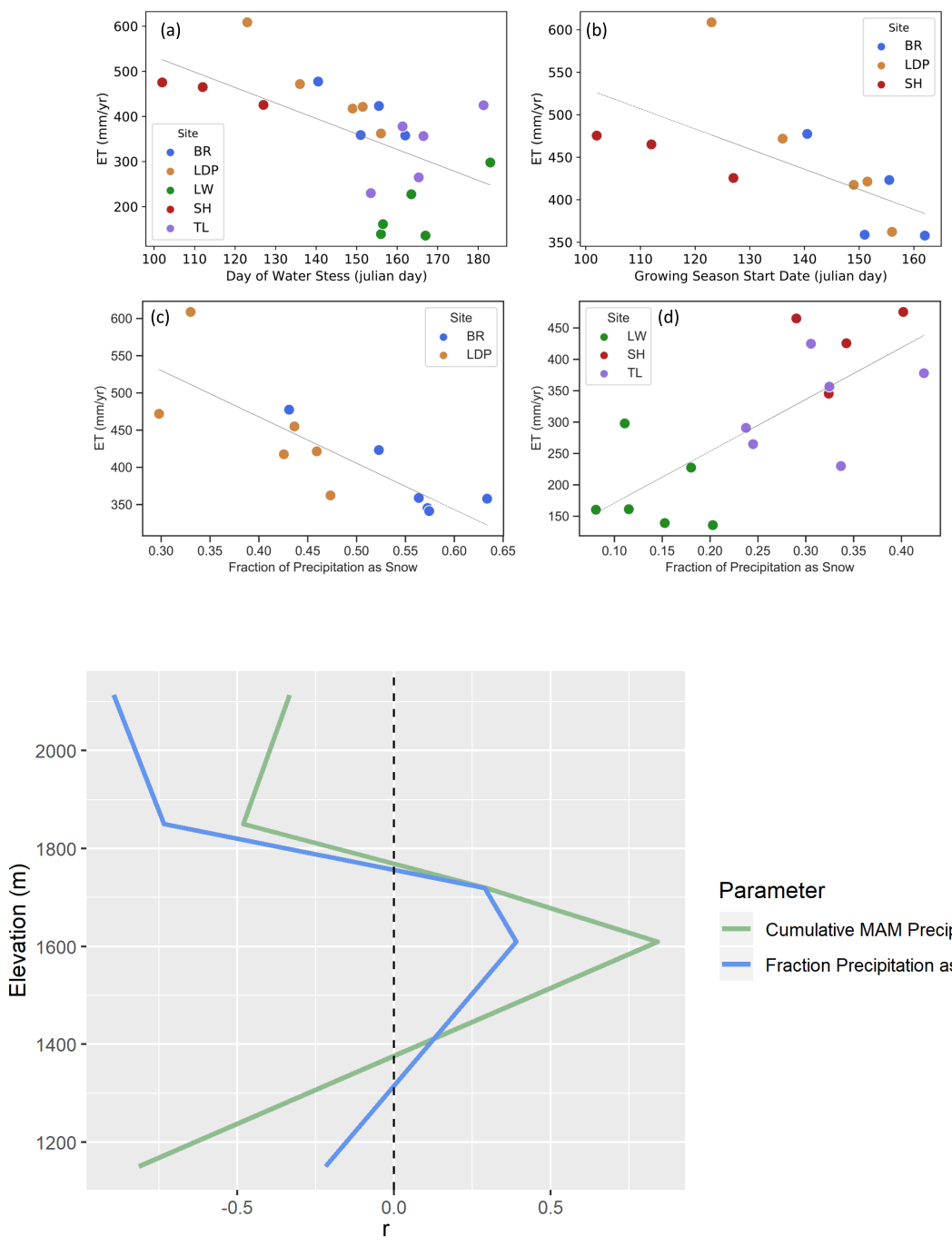

Parameter

- Cumulative MAM Precipitation

- Fraction Precipitation as Snow

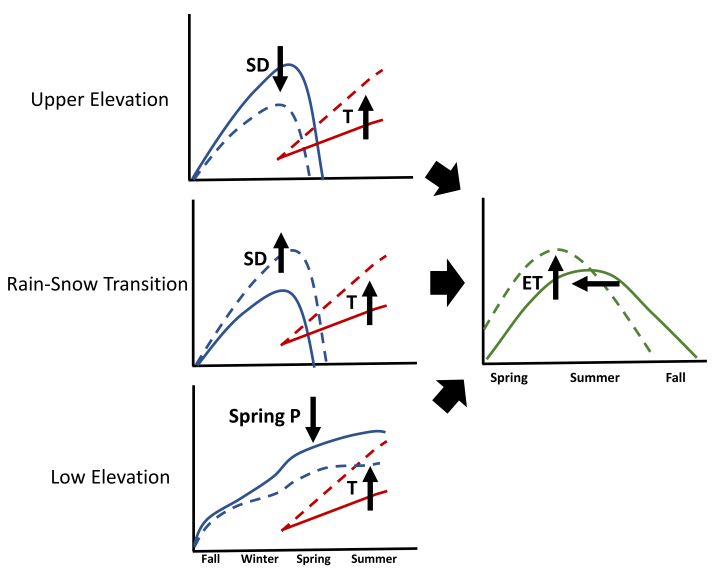

